\title{
Subtipos de adolescentes con trastornos por uso de sustancias y comorbilidad psiquiátrica utilizando los análisis de cluster y discriminante de perfiles MMPI-A
}

\section{Subtypes of adolescents with substance use disorders and psychiatric comorbidity using cluster and discriminant analysis of MMPI-A profiles}

\author{
ERnesto Magallón-Neri *,*; Rosa Díaz *; Maria Forns **; \\ JaVier Goti *; Gloria Canalda*; Josefina

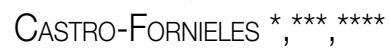

*Department of Child and Adolescent Psychiatry and Psychology, Institute of Neurosciences Hospital Clínic Universitari of Barcelona, SGR1119 and Biomedical Research Center in Mental Health Network CIBERSAM, Spain. ${ }^{* *}$ Department of Personality, Assessment and Psychological Treatment, Faculty of Psychology, University of Barcelona, Spain.

***IDIBAPS (Institut d'Investigacions Biomèdiques August Pi Sunyer), Barcelona, Spain.

${ }^{\star \star \star \star \star}$ Department of Psychiatry and Clinical Psychobiology, Universitat de Barcelona.

Enviar correspondencia a:

Ernesto Magallón-Neri.

Department of Child and Adolescent Psychiatry and Psychology.

Hospital Clínic Universitari of Barcelona.

C/ Villarroel 170, Barcelona 08036, Spain. emagallonneri@ub.edu

\section{Resumen}

El objetivo principal de este estudio fue replicar y ampliar los resultados de estudios previos sobre subtipos de adolescentes con trastorno por uso de sustancias (TUS), de acuerdo con sus perfiles de personalidad en el Minnesota Multiphasic Personality Inventory for adolescents (MMPI-A). Sesenta pacientes con TUS y comorbilidad psiquiátrica (41.7\% hombres, edad media $=15.9$ años) completaron el MMPI-A, el Teen Addiction Severity Index (T-ASI), el Child Behaviour Checklist $(\mathrm{CBCL})$, y entrevistas para obtener diagnósticos DSM-IV y medidas del nivel de uso de sustancias. El perfil general de personalidad MMPI-A mostró elevaciones moderadas en las escalas de Desviación Psicopática, Depresión e Histeria. El análisis de cluster jerárquico reveló cuatro perfiles (acting-out, 35\% de la muestra; disorganized-conflictive, 15\%; normative-impulsive, 15\%; y deceptive-concealed, 35\%). Se encontraron asociaciones entre el cluster 1 , la sintomatología externalizante a nivel clínico del $\mathrm{CBCL}$ y los trastornos de conducta, así como entre el cluster 2 y un nivel clínico de sintomas internalizantes y externalizantes del CBCL. El análisis discriminante mostró que las escalas del MMPI-A Depresión, Desviación Psicopática y Psicastenia, clasificaron correctamente el $90 \%$ de los pacientes dentro de los subgrupos obtenidos.

Palabras clave: trastorno por uso de sustancias (TUS), MMPI-A, análisis de cluster jerárquico, análisis discriminante, adolescentes.

\section{Abstract}

The main aim of this study was to replicate and extend previous results on subtypes of adolescents with substance use disorders (SUD), according to their Minnesota Multiphasic Personality Inventory for adolescents (MMPI-A) profiles. Sixty patients with SUD and psychiatric comorbidity $(41.7 \%$ male, mean age $=15.9$ years old $)$ completed the MMPI-A, the Teen Addiction Severity Index (T-ASI), the Child Behaviour Checklist (CBCL), and were interviewed in order to determine DSMIV diagnoses and level of substance use. Mean MMPI-A personality profile showed moderate peaks in Psychopathic Deviate, Depression and Hysteria scales. Hierarchical cluster analysis revealed four profiles (acting-out, 35\% of the sample; disorganized-conflictive, 15\%; normative-impulsive, 15\%; and deceptive-concealed, 35\%). External correlates were found between cluster 1, CBCL externalizing symptoms at a clinical level and conduct disorders, and between cluster 2 and mixed $\mathrm{CBCL}$ internalized/externalized symptoms at a clinical level. Discriminant analysis showed that Depression, Psychopathic Deviate and Psychasthenia MMPI-A scales correctly classified 90\% of the patients into the clusters obtained.

Key words: substance use disorder (SUD), MMPI-A, hierarchical cluster analysis, discriminant analysis, adolescents. 
l: adolescents, substance use disorders (SUD) are associated with a wide variety of psychological, social and interpersonal problems that make intervention particularly complex and often produce poor treatment outcomes (Hawkins, 2009; Waldron \& Turner, 2008), especially in adolescents with comorbid psychiatric disorders (Couwenbergh, Van den Brink, Zwart, Vreugdenhil, Van Wijngaarden-Cremers $\&$ Van der Gaag, 2006). Indeed, the increase in dual disorders among adolescents is becoming a major health problem, not only for the individuals and families concerned but at the community level as well, since it generates a high social cost (EMCDDA, 2010; Martino, Carroll, Kostas, Perkins \& Rounsaville, 2002).

Substance use disorders have been associated with both internalizing and externalizing symptoms (King, lacono \& McGue, 2004; Martel, Pierce, Nigg, Jester, Adams, Puttler et al. 2009), and particularly with antisocial tendencies, depression, emotional dysregulation and lack of impulse control (Kirisci, Tarter, Mezzich \& Vanyukov, 2007; Muñoz-Rivas, Graña, Peña \& Andreu, 2002). Comorbidity between SUD and other psychiatric diagnoses increases the risk of unprotected sexual intercourse, suicide, violence and delinquency, among other negative consequences (Estévez \& Emler, 2011; Hawkins, 2009). Given the special complexity of treating dual disorders in adolescents, several authors have recently emphasized the need to integrate both mental health and substance use components into treatment in a coordinated and flexible way (Hawkins, 2009; Waldron \& Turner, 2008). The analysis of subtypes of adolescents with SUD and comorbid diagnoses according to personality traits is an understudied field, and greater knowledge in this regard could help to design different treatments for different types of patients (Conrod, Castellanos-Ryan \& Strang, 2010).

The MMPI (Minnesota Multiphasic Personality Inventory) is one of the most widely used instruments to assess personality and psychopathology in the field of SUD, the version for adolescents and youngsters (MMPI-A; Butcher, Williams, Graham, Archer, Tellegen, Ben-Porath et al., 1992), is also used for assessment both in clinical and correctional contexts (Archer, 2005; Stein \& Graham, 2005). Both instruments basically comprise three validity scales [Lie (L), Infrequency (F) and Defensiveness (K)] and ten clinical scales [Hypochondriasis (1 Hs), Depression (2 D), Hysteria (3 Hy), Psychopathic Deviate (4 Pd), Masculinity-Femininity (5 Mf), Paranoia (6 $\mathrm{Pa})$, Psychasthenia (7 Pt), Schizophrenia (8 Sc), Hypomania (9 Ma), and Social Introversion (0 Si)]. The MMPI-A includes two additional drug-related scales, which complement the earlier MacAndrew Alcoholism-Revised scale (MAC-R). These two scales are the Alcohol/Drug Problem Acknowledgment (ACK) scale, which identifies self-recognition of problems related to drugs (obvious items), and the Alcohol/Drug Problem Proneness (PRO) scale, which identifies susceptibility to developing drug problems (subtle items). Both scales have been validated and may be of great help in designing individualized SUD treatment plans, as they provide information related to patients' insight into their substance use problems and their motivation to change (Gallucci, 1997; Micucci, 2002; Stein \& Graham, 2005).
Although there are several studies of MMPI and MMPI-A personality profiles in adolescents and young adults (Espelage, Cauffman, Broidy, Piquero, Mazerolle \& Steiner, 2003; Mohíno, Kirchner \& Forns, 2008), as well as in patients with SUD (Gallucci, 1997; Walfish, Massey \& Krone, 1990), only two studies have attempted to identify specific subgroups of adolescents with SUD through the MMPI (Massey, Walfish \& Krone, 1992) or the MMPI-A (Passetti, 2002). Both studies used clustering methods and were conducted mostly with Caucasian (93\% and 75\% respectively) males (66\% and 76\% respectively) initiating residential treatment, and who had mainly been referred from the court system. In both samples the primary drug of choice was cannabis (69\% and 89\% respectively), followed by alcohol (18\% and 78\% respectively). Neither of these studies specifically addressed clinicallyreferred dual disordered patients.

The study by Massey et al. (1992) identified a three-cluster structure in MMPI scales from SUD adolescents: a) the first subgroup (16\%) showed a high level of psychopathology and a wide variety of symptoms, with main peaks on the 1 $\mathrm{Hs}$ and $4 \mathrm{Pd}$ scales, as well as significant elevations on the 8 Sc, 2 D, 3 Hy and 7 Pt scales; b) the second subgroup (39\%) showed an impulsive or acting-out personality style, with a peak on the $4 \mathrm{Pd}$ scale and significant elevations on the 9 $\mathrm{Ma}, 7 \mathrm{Pt}$ and $8 \mathrm{Sc}$ scales; and c) the third subgroup (45\%) showed non-clinically significant elevations.

Passetti (2002) found a four-cluster structure using the MMPI-A. The first cluster (22\%) was composed of patients with a 'fake-good' attitude (minimization of clinical problems and positive self-presentation), with a moderate-low clinical profile peaking on the $4 \mathrm{Pd}$ and $3 \mathrm{Hy}$ scales. The second cluster (31\%) included apparently sincere patients with non-clinical elevations. The third cluster (21\%) consisted of patients showing broad and intense emotional stress and severe psychopathological symptoms, with elevations mainly on the $4 \mathrm{Pd}, 6 \mathrm{~Pa}, 8 \mathrm{Sc}$ and $9 \mathrm{Ma}$ scales. The fourth cluster $(26 \%)$ was described as having an impulsive acting-out personality style, with a peak on the $4 \mathrm{Pd}$ scale and moderateto-high levels of emotional distress.

The present study has three aims. First, to replicate and extend previous findings about typologies of adolescents with SUD by applying cluster and discriminant analysis methods to MMPI-A scores of dual diagnosed adolescents. Second, to explore the external validity of the clusters identified by comparing the respective patterns of substance use, diagnostic categories, externalizing and internalizing symptoms, and the severity of drug-related problems. Thirdly, to compare the mean scores of the different clusters on the MMPI-A drug-related scales (MAC-R, ACK and PRO).

On the basis of previous studies, we expected to find a general MMPI-A profile with a peak on the $4 \mathrm{Pd}$ scale (Walfish et al., 1990) and moderate-to-significant elevations on the 2 D, 3 Hy and 9 Ma scales (Gallucci, 1997). Additionally, we expected to find a cluster distribution similar to that of Passetti (2002), who also used the specific instrument for adolescents (MMPI-A). We hypothesized there would be congruent external clinical correlates (diagnoses and CBCL symptoms) for some of the clusters found (Passetti, 2002). 
Finally, we expected that some of the clusters would show a high score on the drug-related ACK scale, indicating an overt recognition of drug problems, while other clusters would obtain a lower score on ACK in comparison with PRO, showing a predisposition towards drug problems with a low insight (Micucci, 2002).

\section{Method}

\section{Participants}

Potential subjects for this study were patients consecutively admitted to the Adolescent Addictive Behaviour Unit of the Child and Adolescent Psychiatry and Psychology Department of an urban, public general hospital between September 2006 and March 2008. In this unit most patients are treated as outpatients, although approximately $30 \%$ need short periods as inpatients on the psychiatric ward or in the day-care hospital in order to treat acute psychiatric symptoms or to help them break their drug habit.

The following criteria were defined for participation in the study. Inclusion criteria: age 13-18 years, meeting DSM-IV-TR (APA, 2002) diagnostic criteria for SUD (abuse and/or dependence) and signing informed consent forms. Exclusion criteria: presence of functional mental retardation or acute psychopathological disturbances (psychotic state, severe depression). All the participants in this study, met criteria for at least one SUD (mainly related to alcohol and cannabis use), although not all of them reached a SUD level in each of the assessed substances. Patients presenting with acute psychopatological disturbances (severe psychotic state or depression) during the first month of intervention in the UNICA-A were excluded, because of potential interference effect in the psychological evaluation. However, this did not exclude patients diagnosed with stabilized non-acute depression or psychotic disorders of participating in this study.

Out of a total of 91 SUD patients admitted for treatment to the Adolescent Addictive Behaviour Unit, 84 fulfilled the inclusion criteria. Seven of them refused to complete a significant portion of the evaluation protocol and 11 patients were referred for more intensive treatment in a residential centre before finishing the evaluation. A further six subjects were excluded from the final statistical analysis because of invalid MMPI-A profiles, due to a $T$ score $>65$ on either $L$ (Lie) or K (Defensiveness) scales. Consequently, 60 patients were included in the final analysis (41.7\% male, mean age 15.9 , $\mathrm{SD}=1.20$, range $13-18$ years old). Although a comprehensive analysis of patients' profile among excluded patients was not feasible, we reported a higher frecuency of male subjects (68.0 vs $41.7 \%$ in the included subjects) among them. Primary comorbid diagnosis of attention deficit hyperactive disorder (36.0\% vs. $20 \%$ ) or conduct disorder (28.0 vs. $15.0 \%$ ) was more prevalent among excluded patients, too, whereas no significant differences in age (mean age 15.9, SD $=1.24$ years old) were found.

\section{Instruments}

Psychiatric diagnosis. Initial diagnoses were based on the Spanish version of the Kiddie-SADS semi-structured diagnostic interview for children and adolescents. This instrument has shown good reliability and validity for present and lifetime disorders, as well as good internal consistency (Ulloa, Ortiz, Higuera, Nogales, Fresán, Apiquian, et al., 2006). All the subjects were diagnosed by the clinical staff of the child and adolescent psychiatry department of a urban public hospital, according to DSM-IV-TR criteria.

Socio-demographic data. Data regarding age, gender and socio-economic status were obtained through semistructured interviews adapted to Spanish (Diaz, CastroFornieles, Serrano, González, Calvo, Goti et al., 2008) from those used in the Collaborative Study on Genetics of Alcoholism (Hesselbrock, Easton, Bucholz, Schuckit \& Hesselbrock, 1999).

Level of substance use. All the subjects fulfilled criteria for at least one SUD. However, it was considered relevant to identify the pattern of use of other subtances. According to the quantity/frequency of use gathered from the semistructured interviews mentioned above (Diaz et al., 2008), the level of use of each drug (tobacco, alcohol, cannabis, cocaine, amphetamine derivatives, and others) was coded into five ordinal categories: 1) No use; 2) Occasional use: at parties, during holidays or special celebrations; 3) Regular use: several times a week for tobacco, almost weekly for alcohol or cannabis, almost monthly for other illegal drugs, with no evidence of drug-related problems; 4) SUP (Substance Use Problems): quantity-frequency and/or situational pattern of drug use which generates some health or psychosocial problems but still sub-diagnostic (according to Shrier, Harris, Kurland \& Knight, 2003); and 5) SUD: a definite diagnosis of abuse or dependence according to DSM-IV-TR criteria (APA, 2002).

Personality. The Spanish version of the MMPI-A, which shows acceptable psychometric properties (Jiménez-Gómez \& Ávila-Espada, 2003), was administered. This instrument contains 478 items assessing personality characteristics and psychopathological symptoms in adolescents. $T$ scores above 65 are considered clinically significant, while $T$ scores between 60 and 65 are considered moderately significant or 'sub-threshold' (Micucci, 2002; Passetti, 2002; Stein \& Graham, 2005).

Severity of addiction. The 142-item Spanish version of the T-ASI (Teen-Addiction Severity Index) (Díaz et al., 2008) assesses the severity of problems arising from substance use in seven domains: drug use, school status, employment problems, family function, peer/social relationships, legal status and psychiatric status, each of which is scored using a five point scale $(0=$ None, $1=$ A little, $2=$ Fair amount, $3=$ Very much, 4 = Extremely/Always). It has been shown to have good reliability and validity in different language versions (Kaminer, 2008). As most of the patients were unemployed during the study period, data relating to the employment subscale were not considered in the analysis. 
Behavioural and emotional symptoms. A Spanish version of the original Child Behaviour Checklist (CBCL) (Achenbach, 1991) was completed by parents to assess adolescent psychopathological symptoms. It consists of two parts: the first assesses social competence through 20 items, the second consists of 120 items related to emotional symptoms or behavioral problems that have occurred in the last 6 months. The respondent evaluates each item on a Likert scale from 0 (not true) to 2 (very often true). The CBCL counts of eight narrow band scales (Anxious/Depressed, Withdrawn/ Depressed, Somatic Complaints, Social Problems, Thought Problems, Attention Problems, Rule-Beaking behavior, Agressive behavior) and two broad band scales (internalizing and externalizing), and has demonstrated moderate internal consistency and good test-retest reliability (Albores-Gallo, Lara-Muñoz, Esperón-Vargas, Cárdenas Zetina, Pérez Soriano \& Villanueva Colin, 2007). For the present analysis, only $T$ scores for the internalizing (Withdrawn, Somatic Complaints and Anxious/Depressed) and externalizing (Delinquent and Aggressive Behaviour) scales were used. $T$ scores above 70 were considered as clinically significant.

\section{Procedure}

The MMPI-A and the other parts of the evaluation protocol were administered by trained staff (holders of Master's or doctoral degrees in clinical psychology) within the first month of the patient's referral to the Addictive Behaviours Unit. All adolescents and their parents signed informed consent forms before entering the study, and confidentiality was ensured. Data collection and procedures were approved by the institutional Ethics Committee.

\section{Data Analysis}

First, a descriptive analysis of the total sample, percentages and frequencies for level substance use and psychiatric comorbidity were calculated. Hierarchical cluster analysis of the ten clinical scales of the MMPI-A was performed using Ward's method (Mohíno et al., 2008; Passetti, 2002), based on squared Euclidean distances implemented to split the group of cases into homogeneous subgroups. The resulting clusters were subjected to a MANOVA, in order to obtain the statistics associated with the size effect estimation according to partial eta-squared $\left(\eta_{p}{ }^{2}\right)$ and statistical power (1- $\beta$ ) (Ferguson, 2009). At the same time a Scheffé's post-hoc contrast was calculated, using $T$ scores, for each validity, clinical and drug-related scale of the MMPI-A, as well as, the internalizing and externalizing CBCL scales, in order to see the differences among the clusters. The Kruskal-Wallis $\mathrm{H}$ test was then used to identify significant differences between clusters on T-ASI scales (drug use, school, family, social, legal, psychiatric), and levels of substance use, due to the ordinal nature of these variables. The $\chi^{2}$ test was used to compare percentages of psychiatric diagnoses between clusters. Fisher's exact test was run for those psychiatric disorders for which the underlying $\chi^{2}$ assumptions were violated. Finally, a discriminant analysis was applied in order to identify which of the ten MMPI-A clinical scales had the greatest predictive value as regards determining cluster membership. All statistical analyses were performed using SPSS 16.0 and the level of significance was set at $p \leq 0.05$.

\section{Results}

\section{Substance use and clinical features of the sample}

Excluding tobacco (for which $83.3 \%$ of patients met criteria for SUP or SUD) the principal drug of abuse was cannabis (85\% SUP or SUD), followed by alcohol (43.3\% SUP or SUD, mainly used in weekend recreational settings), amphetamines or derivatives (36.7\% used them occasionally) and cocaine $(11.7 \%$ of the patients had used cocaine at least once). The comorbid psychiatric diagnoses on Axis I were 28 (46.7\%) adolescents with a diagnosis of conduct disorder (CD) or oppositional defiant disorder (ODD), 12 (20.0\%) with attention deficit hyperactivity disorder (ADHD), 12 (20.0\%) with eating disorders, $6(10.0 \%)$ with adjustment disorders, $5(8.3 \%)$ with mood disorders, 5 (8.3\%) with non-affective psychotic disorders, and 4 (3.3\%) with anxiety disorders. On Axis II, 12 (20.0\%) adolescents met criteria for Cluster B personality disorders.

\section{Mean scores on MMPI-A scales and cluster pro- files}

The mean MMPI-A clinical profile for the total sample showed moderate elevations on the $4 \mathrm{Pd}, 2 \mathrm{D}$ and 3 Hy scales (see Figure 1). The cluster analysis of the ten MMPI-A clinical scales for the 60 subjects yielded two solutions: one of three and one of four subgroups. We chose the four subgroups solution in accordance with the interpretability of the clusters, basing our decision on previous research and taking into account the clinical characteristics of the sample. The four clusters obtained with the ten clinical scales also showed significant differences on validity and drug-related scales (Table 1). The MANOVA analysis was conducted and differ-

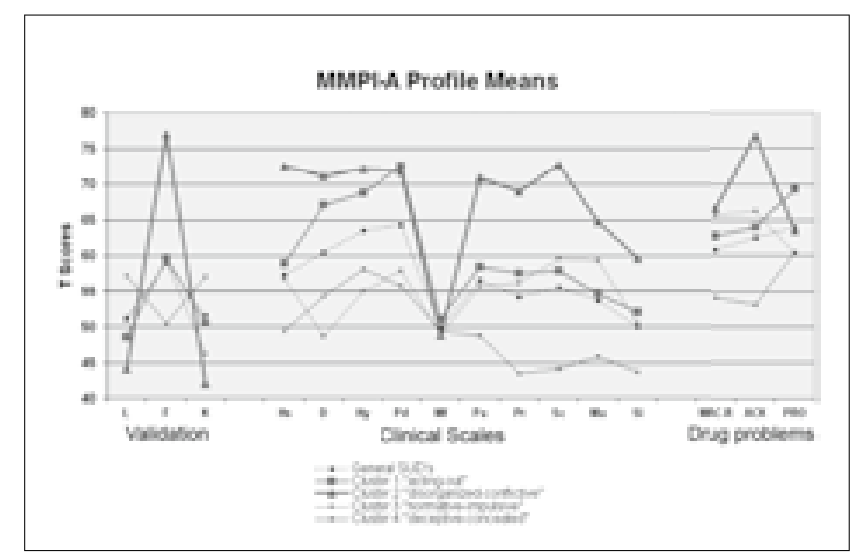

Figure 1. MMPI-A mean profiles for general sample and by cluster. 
Table 1. Descriptive and MANOVA analysis for MMPI-A scales among clusters in general SUD sample and the four clusters.

\begin{tabular}{|c|c|c|c|c|c|c|c|}
\hline $\begin{array}{l}\text { MMPI-A } \\
\text { scales }\end{array}$ & $\begin{array}{c}\text { General SUD } \\
\text { sample } \\
(n=60)\end{array}$ & $\begin{array}{l}\text { Cluster } 1(n=21) \\
\text { "Acting-Out" } \\
\text { Mean (SD) }\end{array}$ & $\begin{array}{c}\text { Cluster } 2(\mathrm{n}=9) \\
\text { "Disorganized-Conflictive" } \\
\text { Mean (SD) }\end{array}$ & $\begin{array}{c}\text { Cluster } 3(\mathrm{n}=9) \\
\text { "Normative-Impulsive" } \\
\text { Mean (SD) }\end{array}$ & $\begin{array}{c}\text { Cluster } 4(n=21) \\
\text { "Deceptive-concealed" } \\
\text { Mean (SD) }\end{array}$ & $\begin{array}{l}\text { MANOVA } \\
\text { F Snedecor } \\
(\mathrm{df}=3,56)\end{array}$ & $\begin{array}{c}\text { Scheffé } \\
\text { Post-hoc } \\
\text { comparisions }\end{array}$ \\
\hline L & 51.25 (9.03) & 48.52 (8.22) & 44.11 (8.81) & $50.78(8.04)$ & 57.24 (6.87) & $7.43^{* * *}$ & $4>2$ \\
\hline $\mathrm{F}$ & 58.97 (11.88) & $59.71(7.80)$ & $77.00(7.50)$ & $59.11(7.20)$ & $50.40(9.40)$ & $21.57^{* * *}$ & $2>1,3,4$ \\
\hline K & $50.90(9.67)$ & $50.48(7.56)$ & 42.11 (8.25) & $46.22(7.87)$ & $57.10(9.02)$ & $8.33^{* * *}$ & $4>2,3$ \\
\hline $1 \mathrm{Hs}$ & 57.32 (11.01) & $58.90(9.33)$ & $72.44(6.67)$ & $56.78(5.80)$ & $49.48(8.31)$ & $16.95^{* * *}$ & $2>1,3,4: 1>4$ \\
\hline $2 \mathrm{D}$ & $60.43(11.48)$ & $67.10(6.48)$ & 71.11 (11.31) & $48.67(7.51)$ & $54.24(8.50)$ & $19.88^{* * *}$ & $1,2>3,4$ \\
\hline $3 \mathrm{Hy}$ & 63.45 (10.20) & $68.71(8.06)$ & $72.11(8.38)$ & $55.00(5.76)$ & $58.10(8.70)$ & $12.81^{* * *}$ & $1,2>3,4$ \\
\hline $4 \mathrm{Pd}$ & $64.30(10.63)$ & $72.43(7.11)$ & $71.78(5.71)$ & $57.89(6.47)$ & $55.71(7.93)$ & $24.80^{* * *}$ & $1,2>3,4$ \\
\hline $5 \mathrm{Mf}$ & $49.83(10.32)$ & $51.00(12.72)$ & $48.89(4.96)$ & $48.89(6.91)$ & $49.48(11.51)$ & 0.14 & $1,2,3,4$ \\
\hline $6 \mathrm{~Pa}$ & $56.50(10.67)$ & $58.48(9.91)$ & $70.89(7.40)$ & $55.67(6.18)$ & $48.71(6.26)$ & $17.22^{* * *}$ & $2>1,3,4$ \\
\hline $7 \mathrm{Pt}$ & 54.17 (10.39) & $57.57(5.75)$ & $69.00(4.24)$ & $56.22(5.01)$ & $43.52(6.03)$ & $49.90^{* * *}$ & $2>1,3,4: 1,3>4$ \\
\hline $8 \mathrm{Sc}$ & $55.55(11.86)$ & $57.86(7.86)$ & $72.67(5.85)$ & $59.56(6.44)$ & $44.19(6.56)$ & $38.68^{* * *}$ & $2>1,3,4: 1,3>4$ \\
\hline $9 \mathrm{Ma}$ & 53.75 (10.65) & $54.57(8.41)$ & $64.67(13.00)$ & $59.33(3.46)$ & $45.86(7.61)$ & $12.41^{* * *}$ & $2>1,4: 3>4$ \\
\hline $0 \mathrm{Si}$ & $50.05(9.62)$ & 52.05 (6.68) & 59.67 (13.06) & $50.44(8.02)$ & 43.76 (6.89) & $8.76^{* * *}$ & $2>4$ \\
\hline MAC-R & 60.75 (11.34) & 62.71 ( 9.98$)$ & $66.67(14.82)$ & $65.67(9.67)$ & $54.14(8.95)$ & $4.68^{* *}$ & $2>4$ \\
\hline ACK & $62.42 \quad 14.10)$ & $63.90(12.96)$ & $76.78(14.11)$ & $66.22(10.23)$ & 53.14 (10.23) & $9.08^{* * *}$ & $2>4$ \\
\hline PRO & 63.97 (11.38) & $69.33(10.91)$ & $63.44(4.44)$ & $60.22(9.49)$ & $60.43(13.02)$ & $2.80 *$ & $1,2,3,4$ \\
\hline
\end{tabular}

Note.

MMPI-A Scales in T scores ; [Lie (L), Infrequency (F) and Defensiveness (K)] Clinical scales [Hypochondriasis (1 Hs), Depression (2 D), Hysteria (3 Hy), Psychopathic Deviate (4 Pd), MasculinityFemininity (5 Mf), Paranoia (6 Pa), Psychasthenia (7 Pt), Schizophrenia (8 Sc), Hypomania (9 Ma), Social Introversion (0 Si), MacAndrew Alcoholism-Revised (MAC-R), Alcohol/Drug Problem Acknowledgement (ACK), Alcohol/Drug Problem Proneness (PRO)]; ${ }^{*} p<.05 ;{ }^{* *} p<.010 ;{ }^{* * *} p<.001$.

ences beween clusters on each MMPI-A sacles were found. The size effect was ranged from moderate to high $\left(\eta_{p}{ }^{2}\right.$ from .31 to .73), and the statistical power (1- $\beta$ ) was high (interval .87 to .99), except fot $5 \mathrm{Mf}$ scale, indicating that differences are relevant.

Clinical MMPI-A profiles for each cluster are shown in Table 1.

The first cluster comprised $35 \%$ of the sample $(n=21$, mean age $=15.76, S D=1.41)$ and was characterized by clinically significant $T$ scores on the $4 \mathrm{Pd}, 3 \mathrm{Hy}$, and $2 \mathrm{D}$ scales. High scores on these scales indicate patients with antisocial behaviour, low impulse control and emotional reactions to conflicts with others; therefore, this cluster reflected actingout personality style.

The second cluster contained $15 \%$ of the sample $(n=9$, mean age $=15.67, S D=1.65$ ) and represented the most psychiatrically disturbed profile. Clinical scales $8 \mathrm{Sc}, 1 \mathrm{Hs}, 3 \mathrm{Hy}$, $4 \mathrm{Pd}, 2 \mathrm{D}$ and $6 \mathrm{~Pa}$ showed $T$ scores above 70, while the $7 \mathrm{Pt}$ and 9 Ma scales had Tscores between 65 and 70 . Accordingly, validity scales showed an inverted ' $\mathrm{V}$ ' configuration with a score of $T>75$ on the $F$ (Infrequency) scale. Due to this broad spectrum of severe clinical symptoms, this cluster was labeled disorganized-conflictive.

The third cluster included $15 \%$ of the sample ( $n=9$, mean age $=16.44, S D=0.88$ ) and showed no clinically significant elevations. This profile only presented moderatehigh scores ( $T$ 59-60) on 8 Sc and $9 \mathrm{Ma}$, reflecting a tendency toward impulsive behaviour, and it was therefore termed normative-impulsive.

The fourth subgroup included the remaining 35\% of the sample $(n=21$, mean age $=16.00, S D=0.83)$ and was characterized, like cluster 3 , by a lack of psychopathological manifestations. This cluster presented slight elevations ( $T$ 55-59) on the $3 \mathrm{Hy}$ and $4 \mathrm{Pd}$ scales and a slight trend towards high $T$ scores on the validity scales $\mathrm{L}$ ( Lie) and $\mathrm{K}$ (Defensiveness), showing a typical 'fake good' profile. This subgroup was therefore called deceptive-concealed.

\section{Inter-cluster comparison for drug-related scales of the MMPI-A (MAC-R, ACK, PRO)}

Two of the MMPI-A drug-related scales (MAC-R and ACK) showed clear statistically significant differences between clusters, with the ACK scale maximizing inter-cluster differences mainly between cluster 2 and 4 (see Figure 1 and Table 1). Additionally, the configuration of ACK and PRO scales differed between clusters: while cluster 1 showed higher scores on PRO (clinically significant) and only moderately significant in cluster 2, 3 and 4; clusters 2 and 3 showed greater scores on ACK (at clinical level in both clusters) (Figure 1).

\section{Inter-cluster comparison in relation to level substance use and severity of addiction (T-ASI)}

Scores on the T-ASI subscales and the level of use (see table 2) of the different substances did not discriminate between the four clusters. Nevertheless, all the clusters showed at least a mean regular use of alcohol, a mean SUP level of use of cannabis, and at least an occasional use of other drugs. Additionally, all the clusters showed moderate to high psychiatric impairment on the corresponding scale of the T-ASI, reflecting the sample's clinical origin.

\section{Inter-cluster comparison for psychiatric diag- noses and $C B C L$ scores}

Only ODD psychiatric diagnose differed significantly between clusters, showing greater prevalence in the first cluster $\left(\chi^{2}=9.42, d f=3 ; p=.023\right)$. With respect to the $\mathrm{CBCL}$ (see table 3 ), there were no significant differences between clusters on externalizing or internalizing scales. However, two of the clusters showed $T$ scores above 70 (clinical significance) on these scales: Cluster 2 on both internalizing (mean $=73.38, \mathrm{SD}=5.60)$ and externalizing (mean $=71.13, \mathrm{SD}=$ 4.35) scales, and cluster 1 only on the externalizing scale (mean $=70.44, \mathrm{SD}=5.98)$. 
Table 2. T-ASI domains and drug use level by clusters and global sample.

\begin{tabular}{|c|c|c|c|c|c|}
\hline Variables & $\begin{array}{l}\text { General } \\
\text { SUD sample } \\
(n=60)\end{array}$ & $\begin{array}{c}\text { Cluster } 1 \\
\text { ( } \mathrm{n}=21) \\
\text { "Acting- } \\
\text { Out" }\end{array}$ & $\begin{array}{c}\text { Cluster } 2 \\
(\mathrm{n}=9) \\
\text { "Disorganized- } \\
\text { Conflictive" }\end{array}$ & $\begin{array}{l}\text { Cluster } 3 \\
(n=9) \\
\text { "Normative- } \\
\text { Impulsive" }\end{array}$ & $\begin{array}{l}\text { Cluster } 4 \\
(n=21) \\
\text { "Deceptive- } \\
\text { concealed" }\end{array}$ \\
\hline & Mean (SD) & Mean (SD) & Mean (SD) & Mean (SD) & Mean (SD) \\
\hline \multicolumn{6}{|l|}{ T-ASI } \\
\hline Drugs & $3.25(0.87)$ & 3.24 (1.09) & $3.33(0.50)$ & $3.33(0.70)$ & $3.19(0.87)$ \\
\hline School & $2.93(0.88)$ & $3.10(0.76)$ & $2.89(0.78)$ & $2.89(0.92)$ & $2.81(1.03)$ \\
\hline Family & $3.07(0.91)$ & $3.14(0.72)$ & $3.11(0.78)$ & $3.22(0.83)$ & $2.90(1.17)$ \\
\hline Social & $2.13(0.96)$ & $2.29(0.71)$ & $2.11(1.05)$ & $2.00(0.86)$ & $2.05(1.20)$ \\
\hline Legal & $1.08(1.60)$ & 1.38 (1.68) & $0.67(1.41)$ & 0.44 (1.33) & $1.24(1.70)$ \\
\hline \multirow[t]{2}{*}{ Psychiatric } & $2.93(0.95)$ & $3.05(0.49)$ & $3.44(0.72)$ & 2.78 (1.39) & $2.67(1.11)$ \\
\hline & N (\%) & N (\%) & N (\%) & N (\%) & N (\%) \\
\hline \multicolumn{6}{|l|}{ Tobacco } \\
\hline No Use & $-(-)$ & $-(-)$ & $-(-)$ & $-(-)$ & $-(-)$ \\
\hline Occasional Use & $3(.05)$ & $-(-)$ & $-(-)$ & $-(-)$ & $3(.14)$ \\
\hline Regular Use & $7(.12)$ & $1(.05)$ & $-(-)$ & $3(.33)$ & $3(.14)$ \\
\hline SUP & $11(.18)$ & $3(.14)$ & $2(.22)$ & $3(.33)$ & $3(.14)$ \\
\hline SUD & $39(.65)$ & $17(.81)$ & $7(.78)$ & $3(.33)$ & $12(.57)$ \\
\hline \multicolumn{6}{|l|}{ Alcohol } \\
\hline No Use & $2(.03)$ & $1(.05)$ & $-(-)$ & $-(-)$ & $1(.05)$ \\
\hline Occasional Use & $16(.26)$ & $5(.23)$ & $5(.55)$ & $-(-)$ & $6(.29)$ \\
\hline Regular Use & $16(.26)$ & $6(.29)$ & $1(.11)$ & $3(.33)$ & $6(.29)$ \\
\hline SUP & $11(.18)$ & $2(.10)$ & $1(.11)$ & $3(.33)$ & $5(.24)$ \\
\hline SUD & $15(.25)$ & $7(.33)$ & $2(.22)$ & $3(.33)$ & $3(.15)$ \\
\hline \multicolumn{6}{|l|}{ Cannabis } \\
\hline No Use & $-(-)$ & $-(-)$ & $-(-)$ & $-(-)$ & $-(-)$ \\
\hline Occasional Use & $3(.05)$ & $1(.05)$ & $-(-)$ & $1(.11)$ & $1(.05)$ \\
\hline Regular Use & $6(.10)$ & $3(.14)$ & $-(-)$ & 1 (.11) & $2(.10)$ \\
\hline SUP & $13(.22)$ & $5(.24)$ & $1(.11)$ & $2(.22)$ & $5(.24)$ \\
\hline SUD & 38 (.63) & $12(.57)$ & $8(.88)$ & $5(.55)$ & $13(.62)$ \\
\hline \multicolumn{6}{|l|}{ Other Drugs ${ }^{a}$} \\
\hline No Use & $26(.43)$ & $8(.38)$ & $6(.67)$ & $-(-)$ & $12(.57)$ \\
\hline Occasional Use & $7(.12)$ & $2(.10)$ & $1(.11)$ & $1(.11)$ & $3(.14)$ \\
\hline Regular Use & $5(.08)$ & $3(.14)$ & $-(-)$ & 1 (.11) & $1(.05)$ \\
\hline SUP & $7(.12)$ & $2(.10)$ & $-(-)$ & $2(.22)$ & $3(.14)$ \\
\hline SUD & $15(.25)$ & $6(.29)$ & $2(.22)$ & $5(.55)$ & $2(.10)$ \\
\hline
\end{tabular}

Note.

T-ASI (Teen Addiction Severity Index) domain range (0 None - 4 Extreme); SUP = Substance Use Problems; SUD = Substance Use Disorders; a mainly cocaine and amphetamine derivates; \% = percentage related to each cluster.

Table 3. Descriptive analysis of CBCL psychopathology and comorbid clinical diagnoses in general SUD sample and the four clusters.

\begin{tabular}{lccccc}
\hline Variables & $\begin{array}{c}\text { General SUD } \\
\text { sample } \\
(\mathrm{n}=60)\end{array}$ & $\begin{array}{c}\text { Cluster } 1 \\
(\mathrm{n}=21) \\
\text { "Acting } \\
- \text { Out" }\end{array}$ & $\begin{array}{c}\text { Cluster 2 } \\
(\mathrm{n}=9) \\
\text { "Disorganized- } \\
\text { Conflictive" }\end{array}$ & $\begin{array}{c}\text { Cluster 3 } \\
(\mathrm{n}=9) \\
\text { "Normative- } \\
\text { Impulsive" }\end{array}$ & $\begin{array}{c}\text { Cluster 4 } \\
(\mathrm{n}=21) \\
\text { "Deceptive- } \\
\text { concealed" }\end{array}$ \\
\hline CBCL & Mean (SD) & Mean (SD) & Mean (SD) & Mean (SD) & Mean (SD) \\
INT scale & $65.54(9.04)$ & $64.06(8.63)$ & $73.38(5.60)$ & $64.86(9.56)$ & $63.53(9.20)$ \\
EXT scale & $69.21(7.62)$ & $70.44(5.98)$ & $71.13(4.35)$ & $68.57(10.48)$ & $67.41(8.98)$ \\
\hline Comorbid & $\mathrm{N}(\%)$ & $\mathrm{N}(\%)$ & $\mathrm{N}(\%)$ & $\mathrm{N}(\%)$ & $\mathrm{N}(\%)$ \\
Diagnoses & & & & & \\
CD & $9(.15)$ & $5(0.24)$ & $-(-)$ & $1(.11)$ & $3(.14)$ \\
ODD & $19(.32)$ & $10(0.48)$ & $1(.11)$ & $3(.33)$ & $5(.24)$ \\
ADHD & $12(.20)$ & $6(0.29)$ & $1(.11)$ & $-(-)$ & $5(.24)$ \\
Anxiety & $4(.06)$ & $2(0.10)$ & $2(.22)$ & $-(-)$ & $-(-)$ \\
Depression & $5(.08)$ & $2(0.10)$ & $1(.11)$ & $1(.11)$ & $1(.05)$ \\
Psychotic & $5(.08)$ & $-(-)$ & $3(.33)$ & $1(.11)$ & $1(.05)$ \\
ED & $12(.20)$ & $4(0.19)$ & $4(.44)$ & $2(.22)$ & $2(.10)$ \\
Cluster B PD & $12(.20)$ & $2(0.10)$ & $4(.44)$ & $3(.33)$ & $3(.14)$ \\
Adjustment & $6(.10)$ & $2(0.10)$ & $-(-)$ & $1(.11)$ & $3(.14)$ \\
Other & $7(.12)$ & $4(0.19)$ & $-(-)$ & $-(-)$ & $3(.14)$ \\
Global & 91 & 37 & 16 & 12 & 26 \\
\hline
\end{tabular}

CBCL (Child Behavior Checklist) scales in T scores; INT = Internalizing; EXT = Externalizing.

Comorbid diagnoses: $\mathrm{CD}=$ Conduct disorder; $\mathrm{ODD}=$ Oppositional Defiant Disorder; $\mathrm{ADHD}=$ Attention Deficit Hyperactive Disorder; ED =Eating disorder; $\mathrm{PD}=$ Personality disorder; $\%=$ percentage related to each cluster.

\section{Discriminant analysis}

Discriminant analysis was applied to assess the relative ability of different clinical scales of the MMPI-A to predict each patient's membership of one of the clusters obtained. Box's $M$ test showed that the groups did not differ in their covariance matrices (Box's $M=23.62 \mathrm{df}=18 ; p=.297$ ), thereby fulfilling the assumption of homogeneity. Discriminant analysis revealed three significant functions that were capable of assigning the patients to their correct cluster on the basis of only three scales: Depression (2 D), Psychopathic Deviate (4 Pd) and Psychasthenia (7 Pt). The first function $\left(\chi^{2}=118.18, \mathrm{df}=9 ; p<=.001\right)$, explains the $82.7 \%$ of the variance and distinguishes patients with higher scores in the scales of $7 \mathrm{Pt}$ y $4 \mathrm{Pd}$. These patients would be mainly assigned to cluster 1 or 2, whilst lower scores in this very function would be more prone join clusters 3 or 4 . The second function $\left(\chi^{2}=33.18, \mathrm{df}=4 ; p<=.001\right)$, explains the $15.7 \%$ of the variance and distinguishes patients with higher scores in the scale of $2 \mathrm{D}$ and significant decrease in the scale $7 \mathrm{Pt}$; high scores in this function could help to discern between cluster 1 and 2 . The third function $\left(\chi^{2}=4.01, \mathrm{df}=1 ; p=\right.$ .045), is marginally significant, providing as little explanation of global variance as $1.7 \%$, and is noted for a weight decline of the scale $4 \mathrm{Pd}$, and a scale weight increase of the scale $2 \mathrm{D}$. On the other hand, the rate of correct reclassification in each cluster (Table 4 ) was around $90 \%$ for clusters 1,3 and 4 , but only $77.8 \%$ for the second cluster (disorganizedconflictive), reallocating 22.2\% of patients in cluster 1 .

Table 4. Discriminant Analysis observed groups and predicted membership (\%)

\begin{tabular}{lcccc}
\hline $\begin{array}{l}\text { Observed } \\
\text { groups }\end{array}$ & $\begin{array}{c}\text { Cluster 1 } \\
(\mathrm{n}=21)\end{array}$ & $\begin{array}{c}\text { Cluster 2 } \\
(\mathrm{n}=9)\end{array}$ & $\begin{array}{c}\text { Cluster 3 } \\
(\mathrm{n}=9)\end{array}$ & $\begin{array}{c}\text { Cluster 4 } \\
(\mathrm{n}=21)\end{array}$ \\
\hline Cluster 1 "acting out" $(\mathrm{n}=21)$ & $90.5 \%$ & $9.5 \%$ & $0 \%$ & $0 \%$ \\
Cluster 2 "disorganized-conflictive" $(\mathrm{n}=9)$ & $22.2 \%$ & $77.8 \%$ & $0 \%$ & $0 \%$ \\
Cluster 3 "normative-impulsive" $(\mathrm{n}=9)$ & $0 \%$ & $0 \%$ & $88.9 \%$ & $11.1 \%$ \\
Cluster 4 "deceptive-concealed" $(\mathrm{n}=21)$ & $4.8 \%$ & $0 \%$ & $0 \%$ & $95.2 \%$ \\
\hline
\end{tabular}

Note.

Overall correct re-classification: 90\%

\section{Discussion}

This study of adolescents with SUD revealed a general MMPI-A profile similar to those obtained in other adolescent and adult SUD samples (Gallucci, 1997; Walfish et al., 1990), showing peaks on $4 \mathrm{Pd}, 3 \mathrm{Hy}$ and $2 \mathrm{D}$, although it lacked the typical increase on the $9 \mathrm{Ma}$ scale. This could be explained by a high representation of females (52\%) and of 'faking good' profiles (35\%) in our study, as well as by the clinical status of the sample, since high $T$ scores on the 9 Ma scale are more usual in male SUD adolescents from correctional settings (Archer, 2005). Moreover, the four clusters found in this study (1: acting out; 2 : disorganized-conflictive; 3: normative-impulsive; and 4: deceptive-concealed) seemed to validate those obtained by Passetti (2002) and, to some extent, the three clusters obtained by Massey et al. (1992), with small differences due to methodological particularities. 
Lastly, discriminant analysis showed that three of the original ten clustering variables ( $2 \mathrm{D}, 4 \mathrm{Pd}$ and $7 \mathrm{Pt}$ ) had the greatest predictive ability as regards the cluster membership of patients. This suggests that a shorter version of the MMPIA might be used in adolescents with SUD to classify them into the clusters obtained. Average correct reclassification (9 of 10) provided by the discriminant was high within the four subgroups obtained. Discriminat analysis reveals that cluster reallocation shows less predicted consistency in cluster 2 . In this case, $77.8 \%$ is attributed to the corresponding cluster, whereas a $22.2 \%$ were classified in cluster 1 . This implies that patients in cluster 2 share some psychopathological characteristics with the acting-out cluster.

As expected, clusters did not differ either in the level of substance use or in the severity of addiction (T-ASI scales). Nevertheless, clear significant differences were found between clusters with respect to some drug-related MMPIA scales (MAC-R and ACK) and more subtle differences in PRO scale $(p<0.05)$. These variables, reflecting mainly insight and/or proneness related to drug problems, are crucial in the design of appropriate interventions for SUD patients (Micucci, 2002). Regarding psychopathology, cluster 1 showed clinically significant $T$ scores ( $>70$ ) on the CBCL externalizing scale, and a significantly higher presence of ODD and CD as a primary or secondary diagnosis in addition to SUD. By contrast, cluster 2 showed clinically significant scores $(T>70)$ on both the externalizing and the internalizing scales of the $\mathrm{CBCL}$. These results corroborate those obtained in other studies (King et al., 2004; Martel et al., 2009) and point to the potential utility of assessing externalizing and internalizing symptoms in order to predict the risk for different subtypes of SUD, in order to design specific interventions (Winters, Stinchfield, Latimer \& Stone, 2008).

In relation to the above paragraph, some of the clusters found in this study are consistent with typologies of patients with alcohol or other SUD, suggesting at least two clear aetiological pathways for developing substance use problems (Babor, Hofmann, Del Boca, Hesselbrock, Meyer, Dolinsky et al., 1992; Sher, Grekin \& Williams, 2005). Cluster 1 corresponds to the antisocial or deviant proneness pathway and is associated with difficulties in impulse control and other frontal functions (Kirisci et al., 2007). Some authors have associated this type of SUD patient with externalizing symptoms (King et al., 2004; Winters et al. 2008) or with cluster B personality disorders (Ball, Tennen, Poling Kranzler \& Rousanville, 1997). In alcoholic typologies, these patients are Cloninger type II or Babor type B (Babor et al., 1992). On the other hand, Cluster 2 in our study corresponds to the negative affect pathway (Sher et al., 2005), sometimes associated with mixed internalizing and externalizing symptoms (King et al., 2004) or with cluster $C$ personality disorders (Ball et al., 1997). This cluster is similar to Cloninger type I or Babor type A alcoholics (Babor et al., 1992).

Various authors have suggested that SUD treatments which are tailored to address specific needs or underlying personality risk factors may lead to better outcomes (Conrod et al., 2010; Winters et al., 2008). Therefore, the analysis of MMPI-A cluster profiles and other clinical and drug-relat- ed variables could help to make tentative cluster-specific therapeutic recommendations (Passetti, 2002). For example, patients in Cluster 1 (acting-out) may need high motivational input to increase their willingness to change their drug use, because they have no real insight into their drug problems and usually show poor therapeutic adherence. The introduction of family members into treatment is necessary to confront these patients with their real problems, and some resistant antisocial cases may need intensive case management or correctional treatment settings (Hawkins, 2009; Liddle, Rowe, Dakof, Henderson \& Greenbaum, 2009). Cluster 2 patients (disorganized-conflictive) are usually chronic patients in need of intensive and flexible integrated treatments (Martino et al., 2002), long-term follow-up and, in some cases, therapeutic residential programs (Hawkins, 2009; Waldron \& Turner, 2008). They usually require psychopharmacological treatment with antipsychotics, antidepressants or mood-stabilizers even before achieving abstinence, due to severe psychiatric symptoms that might otherwise lead to drug use for the purposes of self-medication (Kosten \& Kosten, 2004). By contrast, in Cluster 3 SUD adolescents (normative-impulsive), brief motivational interventions, psychoeducation and urine analyses to monitor drug use may be enough to avoid drug problems (Conrod et al., 2010). Finally, Cluster 4 patients (deceptive-concealed), according to their 'fake good' validity profile (Stein \& Graham, 2005), minimize their problems with drugs and try to drop out of treatment early, after achieving only superficial changes. In these seductive adolescents the therapist must use complex motivational, cognitive and family strategies to engage patients and break their erroneous schemas and narcissistic defenses (Beck et al., 2004, Calvete \& Estévez, 2009).

\section{Strengths and limitations}

The main strength of this study is the replication and validation of previously obtained clusters based on MMPIA scales, this time in a sample of dually diagnosed adolescents. However, this study has several limitations. First, a larger sample would be desirable to show more consistent results. Second, participants in this study are probably not fully representative of dually disordered adolescents, because the proportion of females was similar to that of males. Third, this study is cross-sectional and it is not possible to discern whether psychopathological and personality characteristics are primary or secondary to SUD.

This pilot study found four personality subtypes in adolescent patients with dual diagnosis. The scales of depression, psychasthenia and psychopathic deviation of the MMPI-A made the best discrimination between the four subtypes of adolescents patients.

\section{Conflict of Interest}

The mentioned research has not commercial relationship with tobacco, alcohol or pharmaceutical industry. There is no conflict of interests regarding this for any author. 


\section{Acknowledgments}

This study was supported in part by a grant from the INIFD (National Institute for Research and Training on Drugs), Spanish Ministry of Health, National Plan on drugs (Ref. INT/1525/2003), a grant from the Carlos III Institute (FIS PI07/90428), and a fellowship awarded to the first author from the Commission for Universities and Research of the Department of Innovation of the Generalitat of Catalunya and the European Social Fund.

Thanks to Dr. Joan Guàrdia i Olmos from the University of Barcelona for his guidance with the statistical theory and methodology.

\section{References}

Achenbach, T. M. (1991). Integrative guide for the 1991 CBCL/4-18, YSR, and TRF profiles. Burlington, VT: University of Vermont, Department of Psychology.

Albores-Gallo, L., Lara-Muñoz, C., Esperón-Vargas, C., Cárdenas Zetina, J. A., Pérez Soriano, A.M. \& Villanueva Colin, G. (2007). Validity and Reliability of the $\mathrm{CBCL} / 6-18$. Includes DSM scales. Actas Españolas de Psiquiatría, 35, 393-399.

American Psychiatric Association. (2002). Diagnostic and statistical manual of mental disorders ( $4^{\text {th }}$ ed. rev.). Washington, D.C.: APA.

Archer, R. P. (2005). MMPI-A: Assessing adolescent psychopathology. ( $3^{\text {rd }}$ ed.). Hillsdale, NJ: Lawrence Erlbaum Associates.

Babor, T. F., Hofmann, M., Del Boca, F. K., Hesselbrock, V., Meyer, R., Dolinsky, Z. S. \& Rousanville, B. (1992). Types of alcoholics, I: Evidence for an empirically derived typology based on indicators of vulnerability and severity. Archives of General Psychiatry, 49, 599-608. doi:10.1001/archpsyc. 1992.01820080007002.

Ball, S. A., Tennen, H., Poling, J. C., Kranzler, H. R. \& Rousanville, B. J. (1997). Personality, temperament and character dimensions and the DSM-IV personality disorders in substance abusers. Journal of Abnormal Psychology, 106, 545-553. doi:10.1037/0021843X.106.4.545.

Beck, A. T., Freeman, A., Davis, D. D., et al. (2004). Cognitive therapy of personality disorders. ( $2^{\text {nd }}$ ed.). New York, NY: The Guilford Press.

Butcher, J., Williams, C., Graham, J., Archer, R., Tellegen, A., BenPorath, Y. \& Kaemmer, B. (1992). MMPI-A: Minnesota Multiphasic Personality Inventory-Adolescent: Manual for administration, scoring and interpretation. Minneapolis: University of Minnesota Press.

Calvete, E. \& Estévez, A. (2009). Consumo de drogas en adolescentes: El papel del estrés, la impulsividad y los esquemas relacionados con la falta de límites. Adicciones, 21, 49-56.

Conrod, P. J., Castellanos-Ryan, N. \& Strang, J. (2010). Brief, personality-targeted coping skills interventions and survival as a non-drug user over a 2-year period during adolescence. Archives of General Psychiatry, 67, 85-93. doi:10.1001/ archgenpsychiatry.2009.173.

Couwenbergh, C., Van den Brink, W., Zwart, K., Vreugdenhil, C., Van Wijngaarden-Cremers, P. \& Van der Gaag, R. J. (2006). Comorbid psychopathology in adolescents and young adults treated for substance use disorders: A review. European Child \& Adolescent Psychiatry, 15, 319-328. doi:10.1007/s00787-006-0535-6.

Díaz, R., Castro-Fornieles, J., Serrano, L., González, L., Calvo, R., Goti, J., Kaminer, Y. \& Gual, A. (2008). Clinical and research utility of Spanish Teen-Addiction Severity Index (T-ASI). Addictive Behaviors, 33, 188-195. doi:10.1016/j.addbeh.2007.06.002.

EMCDDA (2010). Informe anual 2010: el problema de la drogodependencia en Europa. Lisboa, Portugal: European Monitoring Centre for Drugs and Drug Addiction.

Espelage, D. L., Cauffman, E., Broidy, L., Piquero, A. R., Mazerolle, P. \& Steiner, H. (2003). A cluster-analytic investigation of MMPI profiles of serious male and female juvenile offenders. Journal of American Academy of Child \& Adolescent Psychiatry, 42, 770-777. doi:10.1097/01.CHI.0000046877.27264.F6.

Estévez, E. \& Emler, N. (2011). Assessing the links among adolescent and young offending, antisocial behaviour, victimization, drug use and gender. International Journal of Clinical and Health Psychology, 11, 269-289.

Ferguson, C. J. (2009). An effect size primer: a guide for clinicians and researchers. Professional Psychology: Research and Practice, 40, 532-538. doi:10.1037/a0015808.

Gallucci, N. T. (1997). On identification of patterns of substance abuse with the MMPI-A scales. Psychological Assessment, 9, 224-232. doi:10.1037/1040-3590.9.3.224.

Hawkins, E. H. (2009). A tale of two systems: Co-occurring mental health and substance abuse disorders treatment for adolescents. Annual Review of Psychology, 60, 197-227. doi:10.1146/annurev. psych.60.110707.163456.

Hesselbrock, M., Easton, C., Bucholz, K. K., Schuckit, M. \& Hesselbrock, V. (1999). A validity study of the SSAGA-a comparison with the SCAN. Addiction, 94, 1361-1370. doi:10.1046/j.13600443.1999.94913618.x.

Jiménez-Gómez, F. \& Ávila-Espada, A. (2003). MMPI-A: Inventario Multifásico de personalidad de Minnesota para adolescentes of Butcher, J. et al., 1992. Madrid: TEA.

Kaminer, Y. (2008). The Teen Addiction Severity Index around the globe: The tower of Babel revisited. Substance Abuse, 29, 89-94. doi:10.1080/08897070802219230.

King, S. M., lacono, W. G. \& McGue, M. (2004). Childhood externalizing and internalizing psychopathology in the prediction of early substance abuse. Addiction, 99, 1548-1559. doi:10.1111/j.13600443.2004.00893.x.

Kirisci, L., Tarter, R., Mezzich, A. \& Vanyukov, M. (2007). Development trajectory classes in substance use disorder etiology. Psychology of Addictive Behaviors, 21, 287-296. doi:10.1037/0893164X.21.3.287.

Kosten, T. R. \& Kosten, T. A. (2004). New medication strategies for comorbid substance use and bipolar affective disorders. Biological Psychiatry, 56, 771-777. doi:10.1016/j.biopsych.2004.07.019.

Liddle, H. A., Rowe, C. L., Dakof, G. A., Henderson, C. E. \& Greenbaum, P. E. (2009). Multidimensional family therapy for young adolescent substance abuse: twelve-month outcomes of a randomized 
controlled trial. Journal of Consulting and Clinical Psychology, 77, 12-25. doi:10.1037/a0014160.

Martel, M. M., Pierce L., Nigg, J. T., Jester, J. M., Adams, K., Puttler, L. I., ... Zucker, R. A. (2009). Temperament pathways to childhood disruptive behavior and adolescent substance abuse: Testing a Cascade Model. Journal of Abnormal Child Psychology, 37, 363393. doi: 10.1007/s10802-008-9269-x.

Martino, S., Carroll, K., Kostas, D., Perkins, J. \& Rounsaville, B. (2002). Dual Diagnosis Motivational Interviewing: a modification of Motivational Interviewing for substance-abusing patients with psychotic disorders. Journal of Substance Abuse Treatment, 23, 297-308. doi: 10.1016/S0740-5472(02)00295-7.

Massey, R. F., Walfish, S. \& Krone, A. (1992). Cluster analysis of MMPI profiles of adolescents in treatment for substance abuse. Journal of Child and Adolescent Substance Abuse, 2, 23-33. doi:10.1300/ J272v02n02_03.

Micucci, J. A. (2002). Accuracy of MMPI-A scales ACK, MAC-R and PRO in detecting comorbid substance abuse among psychiatric inpatients. Assessment, 9, 111-122. doi: 10.1177/10791102009002001.

Mohíno, S., Kirchner, T. \& Forns, M. (2008). Personality and coping in young inmates: a cluster typology. Psychopathology, 41, 157-164. doi: 10.1159/000115953.

Muñoz-Rivas, M. J., Graña, J. L., Peña, M. E. \& Andreu, J. M. (2002). Influencia de la conducta antisocial en el consumo de drogas ilegales en población adolescente. Adicciones, 14,313-320.

Passetti, L. (2002). MMPI-A profiles of adolescents at admission to residential substance abuse treatment. Chicago, ILL: Department of Psychology of Illinois State University.

Sher, K., Grekin, E. \& Williams, N. (2005). The development of alcohol use disorders. Annual Review of Clinical Psychology, 1, 493-523. doi: 10.1146/annurev.clinpsy.1.102803.144107.

Shrier, L. A., Harris, S. K., Kurland, M. \& Knight, J. R. (2003). Substance use problems and associated psychiatric symptoms among adolescents in primary care. Pediatrics, 111, 699-705. doi: 10.1542/peds.111.6.e699.

Stein, L. A. \& Graham, J. R. (2005). Ability of substance abusers to escape detection on the Minnesota Multiphasic Personality Inventory - Adolescent (MMPI-A) in a juvenile correctional facility. Assessment, 12, 28-39. doi:10.1177/1073191104270838.

Ulloa, R. E., Ortiz, S., Higuera, F., Nogales, I., Fresán, A., Apiquian, R., ...de la Peña, F. (2006). Estudio de fiabilidad interevaluador de la versión en español de la entrevista Schedule for Affective Disorders and Schizophrenia for School-Age-Children-Present and Lifetime version (K-SDAS-PL). Actas Españolas de Psiquiatría, 34, 36-40.

Waldron, H. B. \& Turner, C. W. (2008). Evidence-based psychosocial treatments for adolescent substance abuse. Journal of Clinical Child and Adolescent Psychology, 37, 238-261. doi:10.1080/15374410701820133.

Walfish, S., Massey, R. \& Krone, A. (1990). MMPI profiles of adolescent substance abusers in treatment. Adolescence, 25, 567-572.

Winters, K. C., Stinchfield, R. D., Latimer, W. W. \& Stone, A. (2008). Internalizing and externalizing behaviors and their association with the treatment of adolescents with substance use disorders. Journal of Substance Abuse Treatment, 35, 269-278. doi: 10.1016/j. jsat.2007.11.002. 
